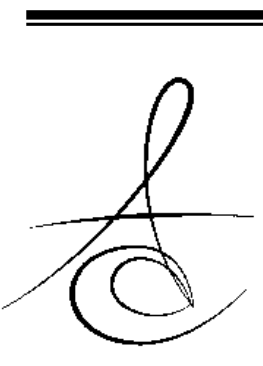

\title{
DENTAL İMPLANTIN PRİMER STABİLİTESİNDE OSSEODENSİFİKASYON KAVRAMI
}

\section{OSSEODENSIFICATION CONCEPT IN PRIMARY STABILITY OF DENTAL IMPLANT}

\section{Öğr. Gör. Gözde IŞIK*}

\author{
Dt. İrem Asya KAFADAR*
}

Prof. Dr. Tayfun GÜNBAY*

Makale Kodu/Article code: 4266

Makale Gönderilme tarihi: 08.01.2020

Kabul Tarihi: 28.05.2020

DOI : $10.17567 /$ ataunidfd.744003
Gözde Işık: ORCID ID: 0000-0001-9572-3049

İrem Asya Kafadar: ORCID ID: 0000-0003-3828-2026

Tayfun Günbay: ORCID ID: 0000-0002-9685-3942

\section{öz}

Osteointegrasyon, canlı kemik doku ile dental implantın yüzeyi arasında kurulan yapısal ve ișlevsel bir bağlantı olarak tanımlanır. Dental implantın stabilitesi, osteointegrasyonun sağlanmasında etkili bir faktördür. Dental implantın mekanik bağlantısı olarak tanımlanan primer stabilite ve hücresel aktivite sonucu oluşan sekonder stabilite, birbirini takip eden süreçlerdir. Primer stabilite kaybı veya bu mekanik stabilitenin sağlanamaması, sekonder stabilite için gerekli olan kemik tamir mekanizmasının bozulmasına neden olur ve bu durum, dental implant kaybına yol açabilir. Son dönemde, tedavi başarısında etkili bir faktör olan primer stabilitenin arttırıması için dental implant yuvasının hazırlanmasında, yeni bir frezleme tekniği tanıtılmışır. Bu sayede, dental implant yuvası hazırlanırken kemik dokunun korunduğu ve yoğunluğunun arttıııdığı belirtilmiştir. Bu derleme, osseodensifikasyon tekniği ve bu tekniğin konvansiyonel osteotomiye avantajları üzerine odaklanmıştır.

Anahtar Kelimeler: İmplantlar; osteotomi; teknikler; derleme

\section{ABSTRACT}

Osseointegration is defined as a structural and functional connection between the bone tissue and the surface of the dental implant. Dental implant stability is an effective factor in achieving osseointegration. Primary stability which defined as the mechanical connection of the dental implant, and secondary stability as a result of cellular activity, are consecutive processes. The primary stability loss or failure results in degradation of the bone repair mechanism that required for secondary stability and this situation may lead to dental implant loss. Recently, a new drilling technique has been introduced in the preparation of dental implant bed to increase primary stability, which is an effective factor in treatment success. It is stated that density of the bone tissue is increased and protected while preparing dental implant bed. This review focuses on the osseodensification technique and its advantages over conventional osteotomy.

Key words: Implants; osteotomy; techniques; review

\section{*Ege Üniversitesi Diș Hekimliği Fakültesi, Ağı̆z, Diș ve Çene Cerrahisi Anabilim Dalı, İzmir}

Kaynakça Bilgisi: Işıı G, Kafadar İA, Günbay T. Dental implantın primer stabilitesinde osseodensifikasyon kavramı . Atatürk Üniv Diş Hek Fak Derg 2021; $31: 316-23$. Citation Information: Ișık G, Kafadar IA, Günbay T. Osseodensification concept in primary stability of dental implant. J Dent Fac Atatürk Uni 2021; 31: 316-23.

\section{GİRIŞ}

Günümüzde, eksik dişlerin dental implantlar yardımıyla tedavisi rutin bir prosedür haline gelmiştir. ${ }^{1}$ Dental implant tedavisinin başarısını belirleyen en önemli belirteçlerden biri osteointegrasyon kavramıdır. ${ }^{1-3}$ İyileşme döneminde dental implantın mikro hareketleri stabiliteyi tanımlar. Bu hareketlerin, 150 mikrometreden $(\mu \mathrm{m})$ daha fazla olması, osteointegrasyon sürecini bozabilir ve kemik doku ile dental implant yüzeyinde fibröz bir bağlantı oluşmasına neden olabilir. ${ }^{2,4} \mathrm{Bu}$ nedenle, primer stabilite, dental implant tedavisinin uzun dönem klinik başarısı ve başarılı bir osteointegrasyon sağlamak için ön şart kabul edilmektedir. ${ }^{5,6}$

\section{Primer ve Sekonder İmplant Stabilitesi}

Dental implantın stabilitesi iki aşamada tanımlanmaktadır. Bunlar;primer stabilite ve sekonder stabilite evresidir. ${ }^{7}$ Primer stabilite, dental implantın cerrahi olarak yerleştirildiği sırada, dental implant yüzeyi ile osteotomi sahasının kemik duvarları arasındaki mekanik bağlantı olarak tanımlanır. ${ }^{8}$

Sekonder stabilite ise dental implant çevresinde kemik dokunun yeniden şekillenmesi ve yeni kemik oluşumu ile gerçekleşir. Dental implantın biyolojik 
bağlantısı olarak adlandırılan sekonder stabilite, dental implantın kemik dokuya osteointegre olmasıyla gerçekleşir.9,10 Osteointegrasyonda, kemik-implant bağlantısının oluşmasında aşamalı olarak gerçekleşen hücresel ve ekstrasellüler aktivite rol alır. ${ }^{11}$ Osteointegrasyon fenomeni olarak adlandırılan bu süreçte, primer stabilite tam olarak ortadan kalkmaz ancak aşamalı olarak mekanik bağlantı azalır ve yerini biyolojik bağlantıya bırakır. ${ }^{2}$ İlk olarak, pıhtı oluşumu ve kalsifiye matrikste trabeküler kemik oluşumunda etkili osteojenik hücre birikimi gerçekleşir. Bu erken trabeküler kemik oluşumu ile primer stabilite azalır ve kademeli olarak yeni oluşmuş kemik doku aracılığıla sekonder biyolojik stabilite ile yer değiştirir. ${ }^{12}$ Böylece, dental implantın biyolojik stabilitesi oluşur ve osteointegrasyon sağlanmış olur. ${ }^{13} \mathrm{Bu}$ fenomenin zaman sekansı henüz tam olarak anlaşılmamıştır. ${ }^{2}$

Bunun yanında, primer stabilite kaybı veya primer stabilitenin düşük olması sekonder stabilite için kemik doku yapım ve yıkım mekanizmasını zayıflatır. Böylelikle, fibröz doku oluşumu ve dental implant kaybı gerçekleşebilir. ${ }^{14} \mathrm{Bu}$ nedenle, primer stabilite, sekonder stabilitenin sağlanması ve başarılı bir osteointegrasyon için büyük önem taşımaktadır. 6,9,15,16

Dental implantın primer stabilitesi, hastaya, cerrahi yönteme ve dental implanta bağlı faktörler ile ilişkilidir. Bunlar; dental implantın yüzey yapısı ve dizaynı; cerrahın deneyimi ve uygulanan cerrahi teknik; alıc kemiğin iyileşme kapasitesi; kemiğin kalitesi ve miktarı olarak açıklanabilir. ${ }^{17-23}$

\section{olan Faktörler}

\section{Hasta ile İlişkili Faktörler}

Primer stabilite, kemik dokunun yoğunluğu ve yapısı ile doğrudan ilişkilidir. ${ }^{17,18}$ Kemik dokunun yoğunluğu, yüksek mineral içeriği ve kollajen bütünlüğü ile açıklanır ve kemik doku ile dental implantın mekanik bağlantısını etkiler. ${ }^{15}$ Bu durum, özellikle posterior maksilla gibi düşük kaliteli kemik yapısında, yüksek yerleştirme torku ile yeterli primer stabilite elde edilmesinin önüne geçer. ${ }^{17} \mathrm{Bu}$ nedenle, dental implant stabilitesini ve uzun süreli klinik başarıyı elde etmek için osteotomi hazırlanırken kemik kütlesini korumak önemlidir. ${ }^{1-3}$

\section{İmplant ile İlişkili Faktörler}

Misch $^{24}$ sınıflamasına göre Tip III, Tip IV gibi düşük kemik yoğunluğuna sahip hastalarda, primer dental implant stabilitesini arttırmak için dental implantın yiv yapısı ve sayısı öne çıkar.20,23 Bunun için, daha derin yiv yapısına sahip ve yüzey keskinliği kemik dokuyu zedelemeyecek yapıda dental implantlar tercih edilir. Bir dezavantaj olarak, bu tasarımın, kemik dokuda apikal ve lateral yönde osteokompresyon oluşturduğu ve primer stabilite kaybına yol açabileceği belirtilmektedir. ${ }^{25-27}$

\section{Cerrahi Yöntem ile İlişkili Faktörler}

Dental implantın primer stabilitesi, uygulanan yerleştirme torkuyla pozitif bir korelasyon gösterir. Norton'a 28 göre sadece 25 Newton santimetre ( $\mathrm{Ncm}$ ) tork, olumlu bir klinik sonuç elde etmek için yeterlidir. Bununla birlikte, dental implantın immediat yüklenmesi planlanıyorsa, en az $32 \mathrm{Ncm}$ 'lik bir yerleştirme torku sağlanmalıdır ve düşük kemik yoğunluğuna sahip bölgelerde bu tork değerinin $45 \mathrm{Ncm}$ olması istenir. ${ }^{29,30}$

Bir diğer önemli faktör osteotomi tekniğidir. ${ }^{5,9,16,19,21-23}$ Dental implant yuvasının hazırlanmasında kullanılan konvansiyonel ostoetomi tekniği, kemik dokunun kesilmesi ve çıkarılması işlemine dayanır. ${ }^{2}$ Bu durum, özellikle Tip III ve Tip IV kemik yapısına sahip çene bölgelerinde primer stabilite kaybına neden olabilir. Bunun önüne geçebilmek adına, dental implanttan daha küçük çapa sahip frez ile osteotomi tamamlanabilir. Ancak bu tekniğin başarısı sınırlıdır. ${ }^{31}$

Dental implant ve kemik doku arasındaki bağlantıyı geliştirmek ve bu sayede, primer stabiliteyi arttırmak için özellikle kemik yoğunluğunun düşük olduğu çene bölgelerinde, basamaklı osteotomi, osteotom aracılığıyla kemik dokunun kondensasyonu veya lateral kondensasyon gibi çeşitli cerrahi teknikler geliştirilmiştir. ${ }^{32-37}$ Ancak bu kondensasyon teknikleri, kemik dokuda hasara neden olmaktadır ve doku iyileşmesini geciktirmektedir. Bu nedenle, bu teknikler ile dental implant tedavisinin başarısı ön görülebilir değildir ve osteointegrasyon sürecinde başarısızlığa yol açabilecekleri bildirilmiştir. ${ }^{34-37}$

Bu nedenle, primer stabiliteyi ve dental implant başarısını arttırmak için yeni teknikler üzerine araştırmalar devam etmektedir. Son dönemde tanitılan osseodensifikasyon kavramı da bu tekniklerden birini oluşturmaktadır. ${ }^{1-3,8}$

\section{Osseodensifikasyon Kavramı}

Osseodensifikasyon, yeni bir dental implant yuvası hazırlama tekniği olarak, 2013 yılında Huwais ${ }^{38}$ tarafından tanıtımıştır. Bu teknik, osteotomi hattında kemik doku deformasyonunu önleyecek şekilde tasarlanmış özel frezler ile uygulanmaktadır. Konik formu ve kesici yüzey yapısı ile bu frezler, dental implant yuvası oluşturulması esnasında kaldırılan kemik dokuyu osteotomi hattının duvarlarına yönlendirir ve o bölgede kemik dokuyu yoğunlaştırır. ${ }^{39} \mathrm{Bu}$ işlem, osteotomi hat- 
tının çevresinde artmış kemik mineral yoğunluğu ile sonuçlanır. ${ }^{40,41}$

Artmış kemik mineral yoğunluğu ile dental implantın yerleştirme torku artar ve mikro hareketleri azalır. Bununla birlikte, daha yoğun kemik yapısında, doku iyileşmesi ve yeni kemik yapımı da hızlanır. Bu durum, kemik-implant bağlantısının ve primer stabilitenin artmasında etkilidir. ${ }^{42-44}$

Osseodensifikasyon tekniği ile özellikle posterior maksilla gibi düşük kaliteli kemik yapısında, osteotomi hattının apikaline doğru kemik doku kondense edilir ve alveoler kemik vertikal yönde genişletilir. ${ }^{38-40,45}$ $\mathrm{Bu}$ sayede, kemik greftlerine olan ihtiyacı azaltarak protetik açıdan istenilen konumda ve boyutta dental implant yerleştirilmesine olanak tanır. ${ }^{40,45}$

Özetle, osseodensifikasyon tekniği, kemik dokunun standart frezlerde olduğu gibi uzaklaştırılması yerine, osteotomi hattından dışarı doğru sıkıştırılarak kompakt bir yapı haline getirilmesi ve dental implant yuvasındaki kemiğin korunarak bir otojen greft olarak kullanılmasıdır. ${ }^{46} \mathrm{Bu}$ teknik ile yeni bir kemik doku yaratılmaz ancak, var olan kemik doku uygun hale getirip korunmuş olur. ${ }^{47}$

Huwais'e ${ }^{38,39}$ göre osseodensifikasyon sırasında alveoler kemik sırtı bütünlüğü korunur ve otojen kemik doku sayesinde alveoler kemik sırtının genişliği de arttırılmış olur. Bu sayede, hem osteotomi bölgesinde kompakt bir kemik doku oluşturulduğu hem de primer stabilitenin arttırıldığı rapor edilmiştir. ${ }^{40,41,46}$ Trisi ve arkadaşları (ark.), ${ }^{48}$ osseodensifikasyon tekniği ile dar alveoler kemik sırtlarında hasar veya doku kaybı oluşmadan geniş çaplı dental implantların yerleştirilebileceğini belirtmişlerdir.

Osseodensifikasyon tekniğinde kemik dokuda viskoelastik bir deformasyon oluşturulduğu ve uygulamayı takiben osteotomi genişliğinin azalarak dental implant yüzeyinde baskı oluştuğu rapor edilmiştir. ${ }^{41} \mathrm{Bu}$ durum, kemik dokudaki geri yaylanma etkisi ile açıklanmaktadır. ${ }^{49}$ Kemik dokuda oluşan bu etki ile mekanik ve biyolojik iyileşme sürecinde osteojenik aktivite artar. Böylece, kemik-implant bağlantısının ve primer stabilitenin arttığı belirtilmiştir. ${ }^{41,50}$

Bunun yanında, konvansiyonel yöntemle yapılan osteotomi sırasında oluşan mikro hasarların onarılmasının 12 haftadan uzun sürdüğü ve farklı olarak, osseodensifikasyon tekniği ile kemik yoğunluğu arttırıldığı için iyileşmenin daha kısa sürede tamamlandığı bildirilmiştir. ${ }^{51}$

\section{Osseodensifikasyon Frezleri Tasarımı}

Bir cerrahi teknik olarak osseodensifikasyon elde etmek için özel frezler geliştirilmiştir. Huwais ${ }^{38,39}$ tarafından tanıtılan ossseodensifikasyon frezleri, konik gövde tasarımına sahiptir ve kademeli olarak artan çaplarda tasarlanmıştır. Bu tasarım, osteotomi sırasında derinlik kontrolünün sağlanmasında yardımcı olmaktadır. ${ }^{42,52}$

Frezin gövdesindeki heliks ve ters yerleşimli kesici alanlar ise, 2 farklı ayarda çalışma imkanı sağlamaktadır. 1,2,42,45,47 Bunlar sırasıyla;

- Yoğunlaştırıcı ayar: Saat yönünün tersi yönde (800-1500 revolution per minute (rpm)) çalışarak kemiği kesmeden kompakt bir şekilde genişlemesini sağlayan bir ayardır. Frezler yoğunlaştırılmış ayarda çalıştığı zaman eksensel bir reaksiyon kuvveti oluşturacak şekilde yapılmıştır. Bu durum, kemiğin genişletilmesi sırasında gelişmiş bir kontrol mekanizması sunmaktadır.1,2,42,45,47

- Kesici ayar: Saat yönünde (800-1500 rpm) çalışarak kemiğin intiyaç duyulan oranda kesilmesini sağlayan bir ayardır. 1,2,42,45,47

\section{Osseodensifikasyon Frez Setinin Özellikleri}

Set, çapları 3,8-4,8 arasında değişen ve VT8VT5 olarak numaralandırılan 12 adet frezden oluşmaktadır. Setin içinde ayrıca 3 ile 20 milimetre (mm) arasında işaretleme olanağı sağlayan lazerli işaretleyici frez ve paralellik ölçümünde kullanılan paralellik pini bulunmaktadır. $38-41$

\section{Osseodensifikasyon Frezi İle Tedavi Protokolü} Endikasyonları

- Geniş tabanlı dar kretler,

- $1 / 1$ oranında trabeküler ve kortikal kemik varlığı,

- Kemik dokuda yeterli oranda kondensasyon sağlamak için en az $2 \mathrm{~mm}$ trabeküler kemik ve en az $4 \mathrm{~mm}$ kalınlığında kemik doku varlığı, istenilen sonucun elde edilmesinde önemlidir. ${ }^{40,41,45}$

\section{Kontraendikasyonları}

- Dar tabanlı ve rezorbe alveoler kemik sırtlarında,

- Osseodensifikasyon tekniği sonrası, 1,5-2 mm'den az bukkal kemik kalınlığı gözleniyorsa kullanımı önerilmez. ${ }^{40,41,45}$

Kortikal yapıdaki Tip I kemikte, sınırlı miktarda trabeküler kemik dokuya sahip çene bölgelerinde veya alveoler kemik tabanı ile sırtın eşit kalınlıkta olduğu rezorbe kemiklerde, osseodensifikasyon tekniği, kemik doku kaybına neden olabilir ve mikro çatlak riski oluşturur. ${ }^{50}$ Bu vakalarda, kemik ogmentasyon yöntemlerinin kullanımı önerilmektedir. ${ }^{40,41}$

Bu yeni tanıtılan dental implant yuvası hazırlama tekniğinde, konvansiyonel osteotomi teknikleriyle benzer olarak standart bir cerrahi motor kullanılır ve 
kemik doku nekrozunu önlemek için irrigasyon uygulanır. ${ }^{41,47,48,52}$

Osseodensifikasyon frezleri, kemik dokunun yapısına göre iki farklı ayardan birinde veya her iki ayarda da kullanılabilir. Frezleme esnasında, artan çaplarda frezler sırası ile kullanılır ve dental implant çapı ile eşit veya yaklaşık $0.7 \mathrm{~mm}$ daha dar frez ile osteotomi tamamlanır. Böylelikle, dental implantın, oluşturulan yuvaya yerleştirilmesi esnasında karşılaşılacak basınç ile primer stabilitenin arttırıldığı belirtilmektedir. 2,49,52

Alveoler kemiğin lateral ve vertikal yönde genişletilmesinde osseodensifikasyon frezlerinin kullanımı Grafik 1 ve Grafik 2'de özetlenmiştir.

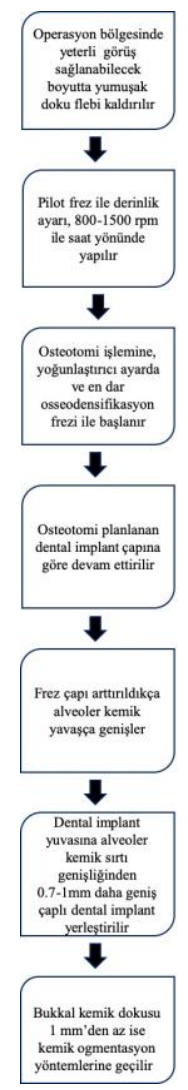

Grafik 1. Alveoler kemiğin lateral yönde genişletilmesinde osseodensifikasyon frezlerinin kullanımı

\section{Osseodensifikasyon Tekniği ile Hayvan}

\section{Çalışmaları}

Osseodensifikasyon tekniğinin primer stabilite üzerine etkisinin incelendiği çalışmalarda, Trisi ve ark., ${ }^{48} 4$ ve 5 yaşlarındaki iki dişi koyunun ilyak kemiğini kullanmıştır. Araştırmacılar, sağ ilyak kemiği kontrol grubu olarak almıştır ve sol ilyak kemik üzerinde ise osseodensifikasyon tekniği uygulamışlardır. Toplamda 20 osteotomi hattının oluşturulduğu çalışmada, gerçek mikro hareket analiz değerleri, çıkarma torku testi ve histolojik analiz ile primer stabilite incelenmiştir. Dental implant kaybının gözlenmediği çalışmada, araştırmacılar, test grubunda çıkarma torkunun daha yüksek olduğunu ve lateral hareketlerde mikro hareketlerin daha düşük olduğunu bildirmişlerdir. Bu nedenle, osseodensifikasyon tekniğinin düşük kemik yoğunluğuna sahip bölgelerde dental implant hareketini azaltarak primer stabiliteyi arttırabileceğini belirtmişlerdir.

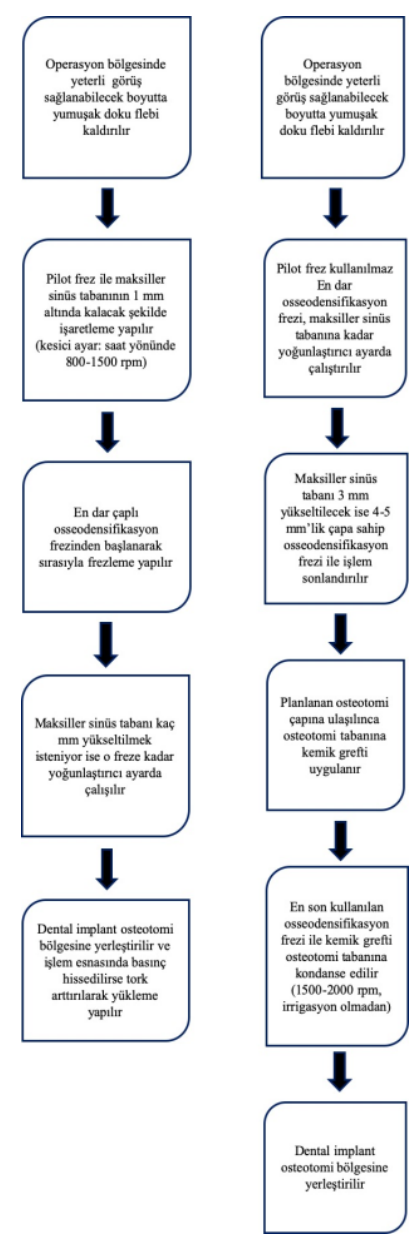

Grafik 2. Alveoler kemiğin vertikal yönde genişletilmesinde osseodensifikasyon frezlerinin kullanımı

Farklı osteotomi tekniklerinin osseodensifikasyon tekniği ile karşılaştırıldığı çalışmalar incelendiğinde olumlu sonuçlar ile karşılaşılmıştır. Huwais ve Meyer, ${ }^{41}$ 12 domuz üzerinde yaptıkları çalışmada, tibia üzerinde standart, ekstraksiyon ve ossedensifikasyon frezleri ile 72 adet dental implant yuvası hazırlamıştır. Primer 
stabilite değerlendirmesinde, rezonans frekans analizi ile yapılan ölçümlerde, yerleştirme ve çıkarma torkunun osseodensifikasyon grubunda daha yüksek olduğu ölçülmüştür. Mikro bilgisayarlı tomografi üzerinde yapılan ölçümlerde kemik mineral yoğunluğunun osseodensifikasyon grubunda daha yüksek olduğu bildirilmiştir. Histolojik incelemede ise dental implant yüzeyindeki kemik yüzdesinin osseodensifikasyon grubunda yaklaşık üç kat daha yüksek olduğu rapor edilmiştir. Bu doğrultuda, araştırmacılar, osseodensifikasyon tekniğinin, primer stabiliteyi, kemik mineral yoğunluğunu ve kemik-implant bağlantısını arttırdığını bildirmişlerdir.

Bir diğer çalışmada, Lahens ve ark., ${ }^{46} 5$ erkek koyunun ilyak kemiğine çift taraflı olarak 15 konikal 15 standart dental implant yerleştirmiştir. Dental implant yuvaları, konvansiyonel osteotomi tekniği ile saat yönünde ve saat yönünün tersi yönde çalıştırılan osseodensifikasyon frezleri kullanılarak oluşturulmuştur. Değerlendirmede, yerleştirme torkunun ve kemik-implant bağlantısının her iki osseodensifikasyon tekniğinde de daha yüksek olduğu gözlenmiştir. Histolojik analizde, otojen kemik dokunun osseodensifikasyon tekniğinde daha belirgin olduğu bildirilmiştir. Araştırmacılar, dental implant yapısından bağımsız olarak, deneysel osseodensifikasyon tekniklerinin, dental implant yuvasında otojen kemiğin yoğunlaştırılmasına yardımcı olduğunu ve bu sayede, primer stabilite ve kemikimplant bağlantısının arttığını bildirmişlerdir.

Cerrahi tekniklerin yanı sıra farklı yüzey yapısına sahip dental implantlarda, kemik-implant bağlantısı ve kemik alan dolum oranı üzerine osseodensifikasyon tekniğinin etkinliği incelenmiştir. Bu çalışmaların birinde, Oliveira ve ark., ${ }^{53} 5$ koyun üzerinde yaptıkları çalışmada, çift taraflı olarak ilyak kemik üzerinde 6 adet dental implant yuvası oluşturmuşlardır. Dental implant yuvaları konvansiyonel osteotomi tekniği ile saat yönünde ve saat yönünün tersi yönde çalıştırılan osseodensifikasyon frezleri kullanılarak oluşturulmuştur. İki farklı yüzey yapısına sahip toplamda 60 dental implantın kullanıldığı çalışmada, yerleştirme torkunun her iki osseodensifikasyon grubunda da yüksek olduğu rapor edilmiştir. Üçüncü ve altıncı haftalarda alınan kemik örneklerinde, kemik parçalarının doğal kemik ve dental implant yüzeyi arasında bir köprü oluşturduğu ve gelişmiş bir kemik remodelasyonu bildirilmiştir. Kemik alan dolum oranının arttığı ve kemik-implant bağlantısında ise farklılık olmadığı rapor edilmiştir. Bu sonuçlar doğrultusunda araştırmacılar, konvansiyonel osteotomiye kıyasla osseodensifikasyon tekniği ile osteointegrasyonun arttığını belirtmişlerdir.

Bir diğer çalışmada, Alifarag ve ark., ${ }^{54} 6$ koyunun ilyak kemiğinde, çift taraflı olarak osteotomi hattı oluşturmuşlardır. İki farklı yüzey yapısına sahip dental implantın kullanıldığı çalışmada, araştırmacılar, konvansiyonel osteotomi tekniği ile osseodensifikasyon frezlerinin kesme ve yoğunlaştırma ayarlarını karşılaştırmışlardır. Değerlendirmede, yerleştirme torkunun, osseodensifikasyon grubunda daha yüksek olduğu bildirilmiştir. Üçüncü haftada alınan histolojik örneklerde, kemik alan dolum oranının ve kemik-implant bağlantısının osseodensifikasyon grubunda daha yüksek olduğu rapor edilmiştir. Bu nedenle, araştırmacılar, osseodensifikasyon tekniği ile biyomekanik stabilite ve osteointegrasyonun arttırıldığını belirtmişlerdir.

\section{Çalışmalar}

Osseodensifikasyon Tekniği ile Klinik

Uzun süreli dişşsizlikte, protetik restorasyon açısından uygun konumda dental implant yerleştirilmesi için alveoler kemik sırtı yeterli genişliğe sahip olmayabilir. Diş çekimi sırasında kemik greftleri kullanılsa bile, göreceli olarak yüksek oranlarda ek ogmentasyon tekniklerine intiyaç duyulabilir. ${ }^{55}$

Koutoizis ve ark., ${ }^{55}$ farklı alveoler kemik genişliğine sahip 21 hastada, osseodensifikasyon tekniği ile 28 adet dental implant uygulamışlardır. Araştırmacılar, alveoler kemikteki genişleme miktarı, yerleştirme torku ve rezonans frekans analizi ile dental implant stabilite değerlerini ölçmüşlerdir. Sonuçlarda, alveoler kemikteki genişleme oranı, koronal kısımda apikale göre daha yüksek bulunmuştur ve dar kretlerde bu oranın daha yüksek olduğu bildirilmiştir. Ortalama yerleştirme torku $61,2 \pm 13,9 \mathrm{Ncm}$ ve dental implant stabilitesi 77 $\pm 3,74$ olarak gözlenmiştir. Klinik olarak, yalnıza iki dental implantta kayıp yaşandığı ve başarı oranının \% 92,8 olduğu rapor edilmiştir. Bu sonuçlara bakıldığında, araştırmacılar, bu tekniğin primer stabiliteyi arttırmada etkili olduğunu ve alveoler kemik sırtı boyutlarını değiştirerek ogmentasyon ihtiyacını azaltabileceğini bildirmişlerdir.

Literatürde, immediat dental implant uygulamasında, osseodensfikasyon tekniği ile primer stabilitenin arttırıldığını rapor eden olgu sunumları yer almaktadır. Bir olgu sunumunda, Machado ve ark., ${ }^{56}$ maksiller birinci molar diş çekimi sonrası yerleştirme torkunu $45 \mathrm{Ncm}$ ve ortalama rezonans indeksini ise 73 olarak ölçmüşlerdir. Operasyon öncesi, operasyon anında ve operasyonu takiben alınan tomografi görüntüleri değerlendirildiğinde, araştırmacılar, osseodensifikasyon ile oluşturulan cerrahi alanın etrafında 
anlamlı bir kemik yoğunlaşması görüldüğünü rapor etmişlerdir. Araştırmacılar, osseodensifikasyon tekniği ile primer stabilitenin arttırıldığını belirtmişlerdir.

Benzer olarak, Da Rosa ve ark., ${ }^{57}$ immediat dental implant uygulamasında osseodensifikasyon tekniğinin etkinliğini değerlendirmişlerdir. Araştırmacılar, periodontal doku kaybı gözlenen iki olguda, maksiller molar ve premolar diş çekimi sonrası, osseodensifikasyon tekniği ile dental implant yuvası hazırlamışlardır. Bu teknikte, düşük devirde ve saat yönünün tersi yönde çalıştırılan frezler ile partiküler otojen kemiğin, lateral ve apikal yönde soket duvarlarına kondense edildiğini bildirmişlerdir. Operasyonu takiben, dördüncü ayda, daimi restorasyon tamamlanmıştır. İki yıllık klinik takipte yumuşak doku hacminin ve diş eti papilla formunun korunduğu ve radyolojik değerlendirmede dental implant çevresinde, yeterli oranda bukkal ve palatinal kemik kalınlığı gözlendiği bildirilmiştir. Bu ön sonuçlara dayanarak, araştırmacılar, osseodensifikasyon tekniği kullanılarak dental implantın primer stabilitesinin arttırılabileceği bildirmişlerdir.

\section{SONUÇLAR}

Osseodensifikasyon kavramı, yeni tanıtılan ve halen araştırılan bir konudur.

Osseodensifikasyon tekniği, kemik yoğunluğunun düşük olduğu çene bölgelerinde, kemik grefti kullanımına gerek olmadan primer stabilitenin sağlanmasında bir alternatif oluşturmaktadır.

Osseodensifikasyon tekniği ile dental implant, kemik yuvasına yerleştirilirken yeterli oranda kemik doku korunur ve bu doku, otojen greft olarak kullanılarak kemik yoğunluğu arttırılır. Bu özelliği ile konvansiyonel osteotomiden üstün olarak mekanik primer stabilitenin elde edilmesi kolaylaşır ve daha iyi bir kemik-implant bağlantısı sunmaktadır.

İleride yapılacak çalışmalar ile dental implant cerrahisinin başarısının artmasında etkili olabilecek bu tekniğin geliştirilmesi ve klinik kullanımının yaygınlaşacağı düşünülmektedir.

Bu çalışma, çalışmayı yürüten tüm yazarlar tarafindan okunmuş ve onaylanmış orijinal bir çalışmadır. Herhangi bir yazar, kurum ya da kuruluş ile çıkar çatışması olmadığını belirtilmek isteriz.

\section{KAYNAKLAR}

1-Gayathri S. Osseodensification technique: A novel bone preservation method to enhance dental implant stability. Acta Scient Dent Sci 2018; 2: 1722.
2-Podaropoulos L. Increasing the stability of dental implants: The concept of osseodensification. Balkan J Dent Med 2017; 21: 133-40.

3-Almutairi AS, Walid MA, Alkhodary MA. The effect of osseodensification and different thread designs on the dental implant primary stability. F1000 Res 2018; 7: 1998.

4-Szmukler-Moncler S, Salama $H$, Reingewirtz $Y$, Dubruille $\mathrm{JH}$. Timing of loading and effect of micromotion on bone-implant interface: review of experimental literature. J Biomed Mater Res 1998; 43:192-203.

5-Degidi M, Daprile G, Piattelli A. Influence of stepped osteotomy on primary stability of implants inserted in low-density bone sites: An in vitro study. Int J Oral Maxillofac Implants 2017; 32: 37-41.

6-Dundar S, Cakmak O, Solmaz MY. Primer stabilizasyonu olan ve olmayan implantlarda kemik implant kaynaşmasının biyomekanik incelenmesi: in vivo bir çalışma. Atatürk Üniv Diş Hek Fak Derg 2018; 28: 188-93.

7-Mavrogenis AF, Dimitriou R, Parvizi J, Babis GC. Biology of implant osseointegration. J Musculoskelet Neur Interact 2009; 9: 61-71.

8-Trisi P, Berardini M, Falco A, Podaliri Vulpiani M. New osseodensification implant site preparation method to increase bone density in low-density bone: in vivo evaluation in sheep. Dent Imp Dent 2016; 25: 24-31.

9-Al-Sabbagh M, Eldomiaty W, Khabbaz Y. Can osseointegration be achieved without primary stability? Dent Clin North Am 2019; 63: 461-73.

10-Raghavendra S, Wood MC, Taylor TD. Early wound healing around endosseous implants: a review of the literature. Int J Oral Maxillofac Implants 2005; 20: 425-31.

11-Fini M, Giavaresi G, Torricelli P, Borsari V, Giardino R, Nicolini A, Carpi A. Osteoporosis and biomaterial osteointegration. Biomed Pharmacother 2004; 58: 487-93.

12-Atsumi M, Park SH, Wang HL. Methods used to assess implant stability: current status. Int J Oral Maxillofac Implants 2007; 22: 743-54.

13-Tabassum A, Meijer GJ, Walboomers XF, Jansen JA. Evaluation of primary and secondary stability of titanium implants using different surgical techniques. Clin Oral Implants Res 2014; 25: 48792.

14-Lundgren D, Sennerby L, Lundgren AK. The effect of mechanical intervention on jaw bone density. An

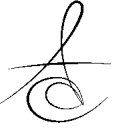


experimental study in the rabbit. Clin Oral Implants Res 1995; 6: 54-60.

15-Lioubavina-Hack N, Lang NP, Karring T. Significance of primary stability for osseointegration of dental implants. Clin Oral Implants Res 2006; 17: 244-50.

16-El-Kholey KE, Elkomy A. Does the drilling technique for implant site preparation enhance implant success in low-density bone? A systematic review. Implant Dent 2019; 28: 500-9.

17-Marquezan M, Osório A, Sant'Anna E, Sauza MM, Maia $L$. Does bone mineral density influence the primary stability of dental implants? A systematic review. Clin Oral Implants Res 2012; 23: 767-74.

18-Chrcanovic BR, Albrektsson T, Wennerberg A. Bone quality and quantity and dental implant failure: $A$ systematic review and meta-analysis. Int J Prosthodont 2017; 30: 219-37.

19-Yoon HG, Heo SJ, Koak JY, Kim SK, Lee SY. Effect of bone quality and implant surgical technique on implant stability quotient (ISQ) value. J Adv Prosthodont 2011; 3: 10-15.

20-Dos Santos MV, Elias CN, Cavalcanti Lima JH. The effects of superficial roughness and design on the primary stability of dental implants. Clin Implant Dent Relat Res 2011; 13: 215-23.

21-Tabassum A, Meijer GJ, Wolke JG, Jansen JA. Influence of the surgical technique and surface roughness on the primary stability of an implant in artificial bone with different cortical thickness: a laboratory study. Clin Oral Implants Res 2010; 21: 213-20.

22-Tabassum A, Walboomers XF, Meijer GJ, Jansen JA. Biological limits of the undersized surgical technique: a study in goats. Clin Oral Implants Res 2011; 22: 129-34.

23-Elias CN, Rocha FA, Nascimento AL, Coelho PG. Influence of dental implant shape, surface morphology, surgical technique and bone quality on the primary stability of dental implants. J Mech Behav Biomed Mater 2012; 16: 169-80.

24- Misch CE. Bone density: A key determinant for clinical success. In: Misch $\mathrm{CE}$, editor. Contemporary Implant Dentistry, 2nd ed. St Louis: CV Mosby Company; 1999. p. 109-18.

25-Abuhussein H, Pagni G, Rebaudi A, Wang HL. The effect of thread pattern upon implant osseointegration. Clin Oral Implants Res 2010; 21: 129-36.

26-Lan TH, Du JK, Pan CY, Lee HE, Chung WH. Biomechanical analysis of alveolar bone stress around implants with different thread designs and pitches in the mandibular molar area. Clin Oral Investig 2012; 16: 363-9.

27-Wu SW, Lee CC, Fu PY, Lin SC. The effects of flute shape and thread profile on the insertion torque and primary stability of dental implants. Med Eng Phys 2012; 34: 797-805.

28-Blanco J, Suarez J, Novio S, Villaverde G, Ramos I, Segade LAG. Histomorphometric assessment in cadavers of the peri-implant bone density in maxillary tuberosity following implant placement using osteotome and conventional techniques. Clin Oral Implants Res 2008; 19: 505-10.

29-Wang L, Wu Y, Perez KC, Hyman S, Brunski JB, Tulu U, Bao C, Salmon B, Helms JA. Effects of condensation on peri-implant bone density and remodeling. J Dent Res 2017; 96: 413-20.

30-Kim SK, Lee HN, Choi YC, Heo SJ, Lee CW, Choie MK. Effect of anodized oxidation or turned implants on bone healing after using conventional drilling or trabecular compaction technique: Histomorphometric analysis and RFA. Clin Oral Implants Res 2006; 17: 644-50.

31-Degidi M, Daprile G, Piatelli A. Influence of under preparation on primary stability of implants inserted in poor quality bone sites: An in vitro study. J Oral Maxillofac Surg 2015; 73: 1084-8.

32-Marković A, Calasan D, Colić S, Stojčev-Stajčić L, Janjić $B$, Mišić $T$. Implant stability in posterior maxilla: bone-condensing versus bone-drilling: a clinical study. Oral Surg Oral Med Oral Pathol Oral Radiol Endod 2011; 112: 557-63.

33-Stavropoulos A, Nyengaard JR, Lang NP, Karring T. Immediate loading of single SLA implants: drilling vs. osteotomes for the preparation of the implant site. Clin Oral Implants Res 2008; 19: 55-65.

34-Toffler M. Site development in the posterior maxilla using osteocompression and apical alveolar displacement. Compend Contin Educ Dent. 2001; 22: 775-80.

35-Boustany CM, Reed H, Cunningham G, Richards M, Kanawati A. Effect of a modified stepped osteotomy on the primary stability of dental implants in low-density bone: A cadaver study. Int J Oral Maxillofac Implants 2015; 30: 48-55.

36-Friberg B, Ekestubbe A, Mellstrom D, Sennerby L. Branemark implants and osteoporosis: A clinical exploratory study. Clin Oral Implants Res 2001; 3: 50-6.

37-Tabassum A, Meijer GJ, Wolke JG, Jansen JA. 
Influence of the surgical technique and surface roughness on the primary stability of an implant in artificial bone with a density equivalent to maxillary bone: a laboratory study. Clin Oral Implants Res 2009; 20: 327-32.

38-Huwais S. Fluted osteotome and surgical method for use. US Patent Application 2013; 18: 196-200.

39-Huwais S. Autografting osteotome. World Intellectual Property Organization, 22 May 2014. WO2014/077920

40-Huwais S. Enhancing implant stability with osseodensification: a case report with 2-year follow-up. Implant Practic 2015; 8: 28-34.

41-Huwais S, Meyer EG. A novel osseous densification approach in implant osteotomy preparation to increase biomechanical primary stability, bone mineral density, and bone-to-implant contact. Int J Oral Maxillofac Implants 2017; 32: 27-36.

42-Kanathila $\mathrm{H}$, Pangi A. An insight into the concept of osseodensification-enhancing the implant stability and success.J Clin Diagnostic Res 2018;12:ZE01 3.

43-Jimbo R, Tovar N, Marin C, Teixeira HS, Anchieta RB, Silveira LM, Janal MN, Shibli JA, Coelho PG. The impact of a modified cutting flute implants design on osseointegration. Int J Oral Maxillofac Surg 2014; 43: 883-8.

44-Trisi P, De Benedittis S, Perfetti G, Berardi D. Primary stability, insertion torque and bone density of cylindrical implant ad modum Brånemark: Is there a relationship? An in vitro study. Clin Oral Implants Res 2011; 22: 567-70.

55-Neelam Das. The new bone drilling concept: Osseodensification (Hydrodynamic Bone Preparation). EC Dent Sci 2019; 18: 2345-55.

46-Lahens B, Neiva R, Tovar N, Alifarag AM, Jimbo R, Bonfante EA, Bowers MM, Cuppini M, Freitas $H$, Witek L, Coelho PG. Biomechanical and histologic basis of osseodensification drilling for endosteal implant placement in low density bone. An experimental study in sheep. J Mech Behav Biomed Mater 2016; 63: 56-65.

47- Hofbauer AM, Huwais S. Osseodensification facilitates ridge expansion with enhanced implant stability in the maxilla: Part II case report with 2year follow-up. Implant Practic 2015; 8: 14-21.

48-Trisi P, Berardini M, Falco A, Vulpiani MP. New osseodensification implant site preparation method to increase bone density in low-density bone: in vivo evaluation in sheep. Implant Dent 2016; 25: 24.
49- Kold S, Bechtold JE, Ding M, Chareancholvanich K, Rahbek O, Søballe K. Compacted cancellous bone has a spring-back effect. Acta Orthop Scand 2003; 74: 591-5.

50-Duncan RL, Turner $\mathrm{CH}$. Mechanotransduction and the functional response of bone to mechanical strain. Calcif Tissue Int 1995; 57: 344-58.

51-Frost HM. A brief review for orthopedic surgeons: Fatigue damage (microdamage) in bone (its determinants and clinical implications). J Orthop Sci 1998; 3: 272-81.

52-Deliverska E, Yordanov B. Osseodensification as an alternative approach in dental implantology for implant sites with insufficient available bone. J of IMAB 2019; 25: 2606-10.

53-Oliveira PGFP, Bergamo ETP, Neiva R, Bonfante EA, Wiltek L, Tovar N, Coelho PG. Osseodensification outperforms conventional implant subtractive instrumentation: a study in sheep. Mater Sci Eng C Mater Biol Appl 2018; 90: 300-7.

54-Alifarag AM, Lopez CD, Neiva RF, Tovar N, Witek L, Coelho PG. Temporal osseointegration: early biomechanical stability through osseodensification. J Orthop Res 2018; 36:2516-2523.

55-Koutouzis T, Huwais S, Hasan F, Trahan W, Waldrop T, Neiva R. Alveolar ridge expansion by osseodensification-mediated plastic deformation and compaction autografting: A multicenter retrospective study. Implant Dent 2019; 28: 349-55.

56-Machado RC, da Gama CS, Batista SH, Rizzo D, Valiense $\mathrm{H}$, Moreira RF. Tomographic and clinical findings, pre-, trans-, and post-operative of osseodensification in immediate loading. Int J Growth Factors Stem Cells Dent 2018; 1:101.

57-da Rosa JCM, Pértile de Oliveira Rosa A, Huwais $\mathrm{S}$. Use of the immediate dentoalveolar restoration technique combined with osseodensification in periodontally compromised extraction sites. Int J Periodontics Restorative Dent 2019; 39: 527-34.

\author{
Sorumlu Yazarın Yazışma Adresi \\ Öğr. Gör. Gözde IŞIK \\ Ege Üniversitesi Diş Hekimliği Fakültesi \\ Ağız, Diş ve Çene Cerrahisi AD \\ Bornova, İzmir, Türkiye \\ Tel no: 0232-311-28-09 \\ E-Posta adresi: gozdech@hotmail.com
}

